\title{
Preservice Science Teachers' Beliefs about Astronomy Concepts
}

\author{
Gulbin Ozkan", Hakan Akcay \\ College of Education, Yildiz Technical University, Istanbul, Turkey
}

Copyright $(2016$ by authors, all rights reserved. Authors agree that this article remains permanently open access under the terms of the Creative Commons Attribution License 4.0 International License

\begin{abstract}
The purpose of this study was to investigate preservice science teachers' conceptual understanding of astronomy concepts. Qualitative research methods were used. The sample consists of 118 preservice science teachers (40 freshmen, 31 sophomores, and 47 juniors). The data were collected with Astronomy Conceptual Questionnaire (ACQ) that includes 13 open-ended questionnaires, and measured various aspects of astronomy such as sun, planets, and moon. Moreover, semi-structured interviews were carried out in order to examine further thoughts of the participants. The results indicate that preservice science teachers have several misconceptions about astronomy concepts. Each misconception is generally based on a common incorrect astronomy knowledge. They have also difficulties with basic definitions and interpret visuals of astronomy concepts. Moreover, there is no difference among the levels of students concerning understanding of astronomy concepts.
\end{abstract}

Keywords Science Education, Astronomy Education, Astronomy, Preservice Science Teachers, Misconceptions

\section{Introduction}

Astronomy, which is one of the oldest science disciplines, has an important role in science education because it has a great influence on perceptions of our surroundings. It also has relation with natural phenomena and helps to scientific development [1]. Understanding of astronomy involves a number of related conceptual areas that are clearly important in relation to children's existing conceptual scopes [2]; they contain concepts of Earth, Universe, Space, Satellite, Galaxy, conception of day and night, seasons, solar system, property of stars etc. In recent years, the importance of astronomy teaching has been gradually increasing in science education, therefore, it has located in science curriculums.

Students' daily lives and experiences, their belief and learning environments, their efforts to grasp concepts using their as yet immature mental skills and other factors conflict with the nature of science itself as well as with the process of how scientific knowledge emerges. In this process, students may have several conceptions about scientific facts [3]. Different researchers use different terms for descriptions of these ideas, such as misconceptions, preconceptions [4], alternative conceptions [5], children's scientific intuitions [6], children's science [7], common sense concepts [8] and spontaneous knowledge [9]. In this study, the misconceptions have been used as a term for determining incorrect ideas about astronomy concepts.

A number of studies that have been indicated that students enter the learning environment with many misconceptions about physics and astronomy [2, 10- 13].

Vosniadou [14] stated that children construct their knowledge of the nature on the basis of two information sources: observations of the world and latter explanations given by other people. In astronomy based units misconceptions are common, because students have no opportunity to observe directly. Students' common misconceptions about astronomy may come from factual misinformation, mythical concepts and language imprecision, misinterpreting sensory information, and incomplete understanding of scientific processes [15].

There are a number of studies about astronomy concepts focusing on different levels: early childhood education [16-20], elementary school students [21-23], high school students [2, 24-27], university students [28-37] and teachers $[28,38]$. The results of these studies indicated that students have misconceptions about basic astronomy concepts. The common misconceptions are as follows: the Moon does not rotate on its axis, Moon only revolves around the Earth and not around the Sun, reason for seasons is the elliptical orbit of the Earth's around the Sun, a planet is an old cold star and there is no difference between a star and a planet. In addition, it can be said that, it relates with students' misconceptions of celestial bodies with their understanding of relative size, motion, and distance.

In this study, we will examine preservice science teachers' conceptions about the astronomy subjects. Several researchers have studied pre-service teachers misconceptions in different astronomy concepts. For instance, Atwood and Atwood [39] studied the night and day 
cycle notion of preservice elementary teachers. This study pointed out that the common alternative conception concerns the revolution of the earth around the sun. Trundle et al. [34] designed experimental research on pre-service elementary teachers about the moon phases. They questioned the effect of instruction about moon phases on the conceptual understandings of those students. Their study indicated that without instruction preservice elementary teachers have mostly a non scientific conception of the moon phases.Trumper [33] also focused on preservice elementary teachers' ideas about basic astronomy concepts. He investigated various astronomical concepts: night and day cycle, moon phases, size of the sun and the earth. This study indicated that pre-service elementary teachers have mostly a non-scientific astronomy conceps. Frede [30], studied preservice elementary teachers' conceptions concerning the celestial bodies and their movements, horizon and vertical and differences between a star and a planet. He indicated many alternative conceptions of preservice elementary teachers with their own words about the astronomical phenomena and definitions. Moreover, Kanli [21] conducted a study to determine the misconceptions of preservice physics and science teachers held extensive misconceptions especially about the reasons for seasons, the Moon's phases, the Moon's phase in the solar eclipse and the Sun's position in the sky.

Preservice science teachers education program is a very critical role to develop teacher candidates' conceptual development of scientific concepts because it has an important effect on students' ability to understand and construct new knowledge of scientific concepts [40]. Because of that, more researches are needed to determine the most effective methods for preparing preservice science teachers. To accomplish this, preservice science teachers' initial concepts should be identified correctly. Future teachers should be aware of their own conceptions about science subjects, because they will transfer their concepts to students.

On the other hand, in a constructivist approach, it is important that future teachers become aware of their own misconceptions in order to change them [30]. In the literature, studies about astronomical visuals, they generally focused participants drawing such as earth, moon, and lunar phases [e.g., 21,24]. Furthermore, there is still not enough work about conceptual understanding in astronomy concerning preservice elementary teachers. This study involves in depth analysis of the misconceptions held by preservice science teachers about various topics in astronomy, such as sun, planets, and moon. This study isdesigned to answer the following research questions:

1. What are the preservice science teachers' beliefs about astronomy concepts?

2. How preservice science teachers interpret the visuals of astronomy concepts?

\section{Materials and Methods}

In this study, qualitative reserach methodologies were used. This approaches helps the researchers to better understand the process of constructing meaning and describe them [41].

\subsection{Sampling}

The sample consists of 118 preservice science teachers (40 freshmen, 31 sophomores, and 47 juniors). Descriptive statistics is shown in Table 1.

Table 1. Descriptive statistics of preservice science teachers

\begin{tabular}{ccccc}
\hline Gender & Freshman(n) & Sophomore(n) & Junior(n) & Total \\
\hline Female & $28(\% 24)$ & $21(\% 18)$ & $44(\% 37)$ & $93(\% 79)$ \\
Male & $12(\% 10)$ & $10(\% 8)$ & $3(\% 3)$ & $25(\% 21)$ \\
\hline Total & $40(\% 34)$ & $31(\% 26)$ & $47(\% 40)$ & $118(\% 100)$ \\
\hline
\end{tabular}

\subsection{Instrumentation}

Astronomy Conceptual Questionnaire (ACQ) was developed to define the students' misconceptions and measure their conceptual understandings about astronomy subjects. Questions were prepared by researchers at the basis of the common conceptions that indicated in the literature and the Turkish Ministry of Education Primary School Science Curriculum (2013). The first version of the questionnaire consisted of 20 open-ended questionnaires. To test the content validity, the test was reviewed by three faculty members specialized in science education. After they examined questions, the questionnaire was given final form which contains 13 questions. Also, before testing for validity and reliability, a pilot study was implemented with 10 students to see students misunderstandings about the concepts. Two researchers analyzed students' answers. In this study, inter-rater reliability was calculated as $95 \%$. The question below is an example from the ACQ (Figure 1).

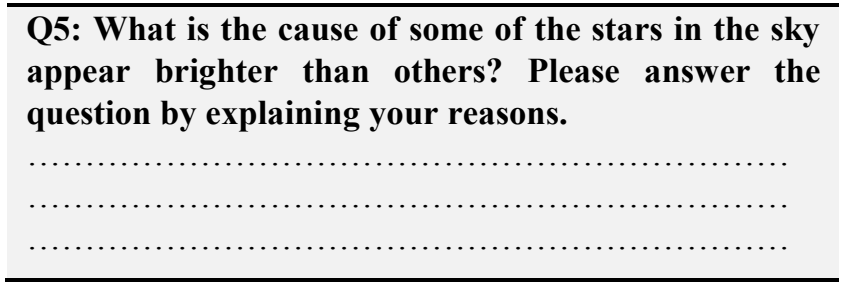

Figure 1. Example of an open-ended test item in the ACQ (Question 5)

In the analysis of the open-ended questions of ACQ, the students' responses were first defined thematically. Content analysis of the data was performed by two researchers. Moreover, the semi-structured interviews were carried out in order to examine further thoughts of the participants. Interviews were conducted with 12 students (6 females and 6 males) that approximately ten percent of participants. 


\subsection{Data Collection Procedure}

First, an Astronomy Conceptual Questionnaire (ACQ) that includes 13 open-ended questions was administered to all students at the same time. Second, semi-structured interviews were carried out in order to examine the thoughts of the preservice teachers on astronomy concepts. For interviews, the students were chosen randomly. During the interviews, more detailed questions of the astronomy concepts were asked in order to reveal students understanding in more detail. The answers received were recorded by the researcher. Each student's interview lasted for approximately 20 minutes.

\section{Findings}

Preservice science teachers responses were categorized around five thematic topics: (1) descriptions of basic concepts associated with astronomy, (2) the sequence of basic astronomy concepts in terms of size, (3) misconceptions and beliefs about astronomy concepts, (4) students' interpretation about astronomical visuals, and (5) the interest to explore other celestial bodies. Results of this study were presented under these categories.
Table 2 indicates percentages of basic astronomy concepts that students' responses. According to these results preservice science teachers have many alternative concepts.

Looking at the table 2 it can be seen that the freshmen students have the most misconceptions. The answers of many students are: "Earth, Mars, Venus is the planet." or, "The Moon is a satellite" or "Galaxy mentioned, is something Milky Way came into my mind". They were trying to answer questions with examples and they answered without accurate definition. Some of the students' responses are given below:

"The universe is the world we live in, it has certain limits." (Student 15)

"Planets are stars in space." (Student 22)

"Space is part of the universe that we can see." (Student 45)

"Satellite is the light source of the planet." (Student 102)

"Galaxy is the name of system which is composed of substances between stars." (Student 73)

The students were asked to put in order of these concepts (universe, planet, satellite, space, and galaxy) in terms of size. Sequences made by the students are given in Table 3 . Table 3 shows that in the students at all three levels have difficulties in sequencing these concepts. In this case, students have lack of knowledge about the basic concepts.

Table 2.Percentages of students concerning their understanding of basic astronomy concepts

\begin{tabular}{|c|c|c|c|c|}
\hline Subject & Misconception(s) & $\mathrm{F}(\%)$ & $\mathrm{S}(\%)$ & $\mathrm{J}(\%)$ \\
\hline \multirow{7}{*}{ Universe } & Universe and space are the same concept. & 22.5 & 19.5 & 14.9 \\
\hline & The universe is a border that covers all substances. & 15.0 & 19.5 & 12.8 \\
\hline & Universe and Milky Way are the same concept. & 7.5 & 12.9 & 8.5 \\
\hline & Universe contains everything which has just living things. & 15.0 & 12.9 & 10.6 \\
\hline & The universe is the earth we live in. & 15.0 & 12.9 & 14.9 \\
\hline & All the planets are all called to universe. & 10.0 & 9.7 & 4.2 \\
\hline & Universe is the name which is given to the gap in space. & 10.0 & 12.9 & 8.5 \\
\hline \multirow{3}{*}{ Planet } & Planets are celestial bodies which have satellite. & 15.0 & 6.4 & 12.8 \\
\hline & Celestial body, which life is in, is called the planet. & 20.0 & 12.9 & 8.5 \\
\hline & Planets are stars in the sky. & 12.5 & 19.5 & 10.6 \\
\hline \multirow{4}{*}{ Satellite } & Satellite is a planet. & 15.0 & 6.4 & 8.5 \\
\hline & Satellite is a star. & 7.5 & 6.4 & 4.2 \\
\hline & Satellite is the helper of the planet, it helps to rotate planet's orbit. & 7.5 & 3.2 & 4.2 \\
\hline & Satellite is the planet's light source. & 7.5 & 12.9 & 10.6 \\
\hline \multirow{3}{*}{ Space } & All areas except the Earth are called space. & 25.0 & 19.5 & 12.8 \\
\hline & Space is finite, the universe is infinite. & 5.0 & 12.9 & 2.1 \\
\hline & All areas except the universe are called space. & 7.5 & 12.9 & 6.3 \\
\hline \multirow{7}{*}{ Galaxy } & Galaxy is the dust clusters in space. & 15.0 & 12.9 & 8.5 \\
\hline & Galaxy is the name of the outer space. & 7.5 & 3.2 & 2.1 \\
\hline & Galaxy is called the orbit of the planet. & 10.0 & 6.4 & 4.2 \\
\hline & Galaxies are small planets orbiting around the planet. & 7.5 & 9.7 & 6.3 \\
\hline & Galaxies is the empty space between the planets and the stars. & 5.0 & 3.2 & 4.2 \\
\hline & Galaxies are circular objects in space. & 15.0 & 12.9 & 10.6 \\
\hline & Galaxy covers the entire space. & 7.5 & 6.4 & 4.2 \\
\hline
\end{tabular}

Note. F: Freshman, S: Sophomore, J: Junior 
Table 3. Percentages of students concerning the sequence of basic astronomy concepts

\begin{tabular}{cccc}
\hline Putting in Order & Freshman(\%) & Sophomore(\%) & Junior(\%) \\
\hline Universe $>$ Galaxy $>$ Space $>$ Planet $>$ Moon & 10.0 & 9.7 & 10.6 \\
Space $>$ Universe $>$ Galaxy $>$ Planet $>$ Moon & 7.5 & 12.9 & 6.3 \\
Universe $>$ Space $>$ Planet $>$ Moon $>$ Galaxy & 7.5 & 6.4 & 8.5 \\
Galaxy $>$ Space $>$ Universe $>$ Planet $>$ Moon & 7.5 & 9.7 & 6.3 \\
Universe $=$ Space $>$ Galaxy $>$ Planet $>$ Moon & 12.5 & 16.1 & 12.8 \\
Universe $=$ Planet $>$ Space $>$ Galaxy $>$ Moon & 12.5 & 9.7 & 10.6 \\
\hline
\end{tabular}

Table 4.Percentages of students misconceptions about astronomy concepts

\begin{tabular}{|c|c|c|c|c|}
\hline Category & Misconception(s) & $\mathbf{F}(\%)$ & $S(\%)$ & $J(\%)$ \\
\hline \multirow{4}{*}{$\begin{array}{l}\text { Properties of } \\
\text { meteors }\end{array}$} & If an object falls to Earth, it is a meteor. & 12.5 & 16.1 & 14.9 \\
\hline & Meteors are always too big. & 15.0 & 12.9 & 10.6 \\
\hline & Meteors are always too small. & 10.0 & 19.5 & 10.6 \\
\hline & Meteors with a core are the black body. & 5.0 & 16.1 & 10.6 \\
\hline \multirow{5}{*}{$\begin{array}{l}\text { Differences } \\
\text { between the } \\
\text { planets and stars }\end{array}$} & The planet has its own brightness. & 15.0 & 19.5 & 14.9 \\
\hline & Stars are always smaller than planets. & 15.0 & 12.9 & 10.6 \\
\hline & Planets do not move the stars slide. & 5.0 & 19.5 & 6.3 \\
\hline & Stars consist of rocks and dust clouds. & 5.0 & 9.7 & 4.2 \\
\hline & If we look at the world we cannot see the planet, but we can see stars. & 17.5 & 16.1 & 10.6 \\
\hline \multirow{5}{*}{$\begin{array}{l}\text { Properties and } \\
\text { Brightness of } \\
\text { stars }\end{array}$} & $\begin{array}{c}\text { Some stars reflect more light from the sun, so these stars shine more than } \\
\text { others. }\end{array}$ & 12.5 & 12.9 & 4.2 \\
\hline & The brightness of stars depends on how much light reflect from the Moon. & 5.0 & 6.4 & 2.1 \\
\hline & $\begin{array}{l}\text { All night long stars reflect light which they receive from the sun during the } \\
\text { day. }\end{array}$ & 17.5 & 19.5 & 10.6 \\
\hline & $\begin{array}{l}\text { The stars reflect the light which they receive from the Moon. Because in the } \\
\text { day time, it does not appear. }\end{array}$ & 10.0 & 12.9 & 8.5 \\
\hline & The stars reflect the light of the other celestial bodies. & 5.0 & 12.9 & 10.6 \\
\hline \multirow{4}{*}{$\begin{array}{l}\text { Cause of the } \\
\text { Moon Phases }\end{array}$} & $\begin{array}{c}\text { Because of the Moon's rotation around its axis, the phases of the Moon } \\
\text { change. }\end{array}$ & 17.5 & 16.1 & 12.8 \\
\hline & $\begin{array}{l}\text { The Moon on different phases is seen because of the Earth's shadow falling } \\
\text { on the Moon. }\end{array}$ & 20.0 & 19.5 & 14.9 \\
\hline & Because of the tidal events, the phases of the Moon change. & 5.0 & 3.2 & 2.1 \\
\hline & $\begin{array}{l}\text { The Moon produces its own light. The phases of the Moon change because of } \\
\text { the Moon's light intensity. }\end{array}$ & 15.0 & 12.9 & 8.4 \\
\hline \multirow{3}{*}{$\begin{array}{l}\text { Properties of the } \\
\text { Sun }\end{array}$} & The sun is a planet. & 15.0 & 25.8 & 12.8 \\
\hline & The sun is both a planet and a star. & 5.0 & 6.4 & 2.1 \\
\hline & The sun is neither a planet nor a star. & 7.5 & 9.7 & 8.5 \\
\hline \multirow{4}{*}{$\begin{array}{l}\text { Center of the } \\
\text { universe }\end{array}$} & Earth is the center of the universe, because there is only life on Earth. & 12.5 & 12.9 & 10.6 \\
\hline & Sun is the center of the universe, because all the planets are around it. & 20.0 & 19.5 & 14.9 \\
\hline & $\begin{array}{c}\text { Milky Way is the center of the universe, because it contains stars, planets and } \\
\text { satellites. }\end{array}$ & 7.5 & 6.4 & 8.5 \\
\hline & None of them, because black hole is the center of the universe. & 2.5 & 6.4 & 4.2 \\
\hline \multirow{3}{*}{$\begin{array}{l}\text { Day and night } \\
\text { circle }\end{array}$} & If the Earth did not rotate its own axis, the life would not be in the world. & 12.5 & 12.9 & 14.9 \\
\hline & If the Earth did not rotate its own axis, seasons would not occur. & 7.5 & 12.9 & 8.5 \\
\hline & The Sun goes around the Earth is the cause of the day and night. & 17.5 & 19.5 & 14.9 \\
\hline \multirow{5}{*}{ Seasons } & Seasons occur thanks to the rotation of the Earth on its axis. & 17.5 & 16.1 & 12.6 \\
\hline & The seasons are caused by the sunlight falling on Earth. & 15.0 & 19.5 & 10.6 \\
\hline & The seasons are caused by the movement of the sun. & 5.0 & 6.4 & 6.3 \\
\hline & The sun goes around the world. & 15.0 & 16.1 & 10.6 \\
\hline & Seasons occur thanks to the Earth's distance from the Sun changes. & 17.5 & 16.1 & 12.8 \\
\hline
\end{tabular}


The misconceptions of students from their responses to the other questions are summarized in Table 4. As seen in Table 4, students have many incorrect beliefs about astronomy concepts. Even some of the questions were left empty by large percentages of students and they said they had no idea.

Some of the students' responses are given below:

"I can understand object is a meteor if it fell to earth, because the meteors are always falling." (Student 18)

"Stars give light and floating, planets are lit up with the satellites." (Student 102)

"Light is larger than it receives from the Moon's star is brighter." (Student 52)

"Stars reflect the light of the heavenly bodies around them. They are appeared at the night because there is no night light." (Student 95)

"Moon consists of phases due to lengthiness or shortenings of the day and night." (Student 64)

"The Sun is a big star, but there are other bigger stars in the Universe. I don't understand why we see only the Sun. (Student 18)

"The sun is a planet, because there are objects revolving around it, such as satellite." (Student 46)
"Blackhole is the center of the universe, because one day everything is will be swallowed and all the scattered planets will gather in this center." (Student 61)

"Earth is the center of the universe, because it is the only area in which life in the universe." (Student 102)

"If the world were not come around its axis people could not walk without falling and assets, objects, creatures could not stand still." (Student54)

Student responses obtained from the visual questions are presented as thematically in Table 5. Students are forced to interpret visuals. It is understood that students do not know the properties of certain celestial bodies. Some of the questions were left empty by large percentages of students and they said they had no idea.

Question 13 were distributed to the two halves of the students. We asked half of them: "Would you like to make a trip to Mars even though you are not likely to go back?" and also we asked other half o them: "Would you like to become one of the scientists who voyage to the Moon?"

Students' thoughs about discovering celestial bodies and interests of the other planets are investigated with these two questions. Students' responses have been summarized in Table 6.

Table 5. Percentages of students' interpretation about astronomical visuals

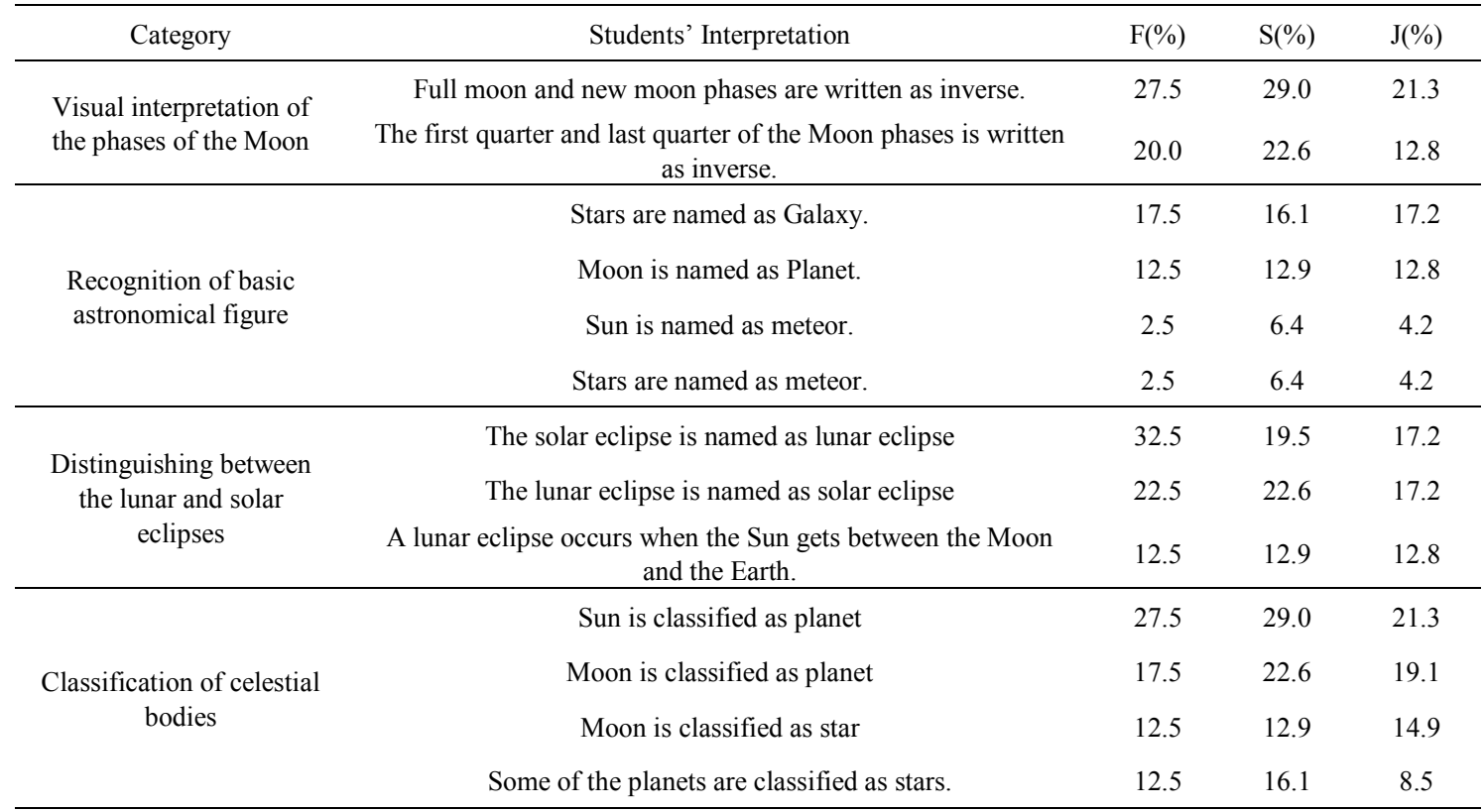

Note. F: Freshman, S: Sophomore, J: Junior

Table 6. Percentages of students' interest to explore other celestial bodies

\begin{tabular}{|c|c|c|c|c|}
\hline & & Freshman(\%) & Sophomore(\%) & Junior(\%) \\
\hline \multirow[b]{2}{*}{ Moon question } & Students who want to go & 50.0 & 48.4 & 51.1 \\
\hline & $\begin{array}{l}\text { Students who don't want to } \\
\text { go }\end{array}$ & 45.0 & 51.6 & 42.6 \\
\hline \multirow[b]{2}{*}{ Mars question } & Students who want to go & 2.5 & 6.4 & 4.2 \\
\hline & $\begin{array}{l}\text { Students who don't want to } \\
\text { go }\end{array}$ & 97.5 & 93.6 & 95.8 \\
\hline
\end{tabular}


Students' responses for Moon arealmost the same percentages. Some of the examples are given below.

"Yes. Because I'm curious. I would like to investigate the Moon like astronauts. I would like to see how is it." (Student 11)

"I don't want. Because I don't know how this place is and what I will encounter." (Student 19)

As seen in Table 6 only one or two people from each grade level has want to go to Mars. Although they have interest, due to thought of staying there students stated that they did not prefer this trip. Some of the students' responses for this question are given below:

"No I do not. Because of the lack of facilities and thought of staying there are made me think.I would not dare to do so." (Student 99)

"I would like to live on Mars. If I knew that I didn't come back the Earth, chances of survival aroused curiosity in me." (Student 100)

In fact, some of the students wonder about living in different places. However, they do not really prefer the situation of staying there. Furthermore,misconceptions that students have also been identified in responses to these questions. For example, student 14 said that "I want to go to the Moon. Because I wonder how I walk without gravity." Some students have a thought that there is no gravity on the Moon.

When looking at findings obtained from both the paper-and-pencil questionnaire and the semi-structured interviews, it can be said that there are no different responses between the levels of students' grades. Although the knowledge of participants changes, what they notice do not change.

\section{Discussion and Conclusions}

In this study we determined some conceptions held by future preservice elementary teachers in astronomy. The preservice science teachers have developed mainly alternative conceptions about astronomical basic concepts and have difficulties with basic definitions.

Trundle et al. [34] and Barnett \& Morran [21] indicated that participants with varied levels of schooling and training from elementary school through in-service teachers have difficulties the cause of moon phases. Ogan-Bekiroglu [29] also found that pre-service physics teachers have misconceptions about Moon, Moon phases and other lunar phenomena. Barnett and Morran [21] pointed out the majority of students began the course with particular understandings of various aspects of the Earth-Moon-Sun system. Some studies indicated that many students was unaware that the universe was expanding $[42,43]$.

The results obtained from the study also exhibit similarities with other research results. Trumper $[2,26]$ conducted a study which investigates day-night cycle, moon phases, seasons, solar eclipse and center of the universe etc. conceptual understandings of high school students. Similar misconceptions were encountered between high school students and preservice science teachers. Kanli [28] also found that the percentages of preservice and in-service teachers' achievement scores are very low on basic astronomy concepts about the reasons for seasons, the Sun's position, the Moon's phases, and the Moon's phase in a solar eclipse. These findings are in agreement with other previous studies in other counties [30,31,33,36,37,39,44,45]. Results of this study also have revealed that the percentages of preservice science teachers' responses are very inadequate on astronomy concepts and student's conceptual understandings are almost parallel in all grades. Indeed, we point out similar alternative conceptions shared by those preservice science teachers. In quantitative sense, our study covers to previous studies.

The results of this study show that preservice science teachers have lack of knowledge, scientific mistakes and misconceptions about astronomy concepts. These concepts are often abstract and require threedimensional thinking. This makes it difficult to learn and comprehend basic astronomy concepts properly [48].

Vosniadou[46] found that elementary school students did not make correct sequencing concepts such as Sun, Earth, Moon and Stars. Similar deficiencies were encountered with preservice science teachers. This study indicated that in the pre-service science teachers at all three levels have difficulties in sequencing some of the celestial bodies.

Visuals have an important place in astronomy education. There is a study that reports visualization has a positive impact on students' understanding [47].Testa, Leccia and Puddu[25] investigated whether iconic features of astronomy images help students in understanding familiar phenomena such as the change of seasons, the solar eclipses and lunar phases. Researchers emphasized the importance of visuals and they reported that secondary school students have difficulties interpreting visuals of astronomy. In this study, it indicated that preservice science teachers have difficulties about interpreting visuals. Teachers play an important role in reducing the misconceptions of students in teaching of astronomy. Therefore, it can be said that if the future teachers have deficiencies about interpreting visuals, their students will have difficulties too.

Celestial bodies are impossible for students to touch and feel.Becasue of that study of astronomy may cause to misconceptions in people' minds. The best way to change the misconceptions is to determine the knowledge of the students in terms of basic astronomy concepts and to ensure an appropriate educational environment. Students' participation in explanation and discussion of these topics as well as experiments and observations is the most effective way of teaching [49].

Although people today have accessed easily to information about astronomy through media such as television, books, and the Internet, their students have lack of knowledge. They don't wonder about other celestial bodies and they have wrong beliefs on these concepts. For this reason, they should be encouraged to raise awareness 
among students. It is the task of science education.

Astronomy teaching is considered difficult because of the large amount of facts and details it contains and because some of the concepts seem like abstracts [47]. Trumper[2] suggested that if these concepts are learned properly in the classroom, every effort must be made to help students to develop their conceptual understanding. Therefore, in order to achieve meaningful progress, learning to identify misconceptions of students is important.

Barnett and Morran [21] pointed out the need that instruction depends on students' pre-existing ideas and supports their reflection and discussion of their ideas. An understanding of knowledge of science teacher candidates in astronomy will be valuable to curriculum writers and preservice teacher training schools. It is critical that pay special attention to preservice teachers' training on astronomy concepts.

Based on the findings of this study, it might be recommended that before starting to teach any subject, it should first be determined whether students have preconceptions or misconceptions about the subject and teaching activities should proceed on the basis of this information (to eliminate existing misconceptions). In the light of these results, learning environment for the students is organized so as to understand the key concepts of astronomy. It can be suggested that concept maps, conceptual change text, analogies may be prepared. In order to develop students' imagination about astronomy, night-sky observations with telescope, videotaped films, computer simulations and many existing internet resources may be used. In curriculums, students should have activities, including prediction, observation and explanation to learn fundamental characteristics of celestial bodies.

The conclusions presented here carry implications for curriculum developers and teacher education. If it is considered that the educational system today is transitioning from traditional instruction to contemporary teaching methods, more rooms should be made for these modern methods in the organization of teaching and education efforts. It might be suggested that constructivist methods and techniques should be developed to shift these misconceptions in future studies.

\section{REFERENCES}

[1] Trumper, R. (2006). Teaching future teachers basic astronomy concepts-seasonal changes-at a time of reform in science education. Journal of Research in Science Teaching, 43(9), 879-906.

[2] Trumper, R. (2001). A cross-age study of junior high school students' conceptions of basic astronomy concepts. International Journal of Science Education, 23(11), 1111-1123.

[3] Ercan, F., Tasdere, A., \&Ercan, N. (2010). Observation of cognitive structure and conceptual changes through word associations tests. Journal of Turkish Science Education, 7(2), 138-154.

[4] Novak, J. D. (1977). A theory of education. Ithaca, NY: Cornell University Press.

[5] Driver, R., \& Easley, J. (1978). Pupils and paradigms: A review of literature related to concept development in adolescent science students. Studies in Science Education, 5(1), 61-84.

[6] Sutton, C. R. (1980). The learner's prior knowledge: a critical review of techniques for probing its organization. European Journal of Science Education, 2, 107-120.

[7] Gilbert, J. K., Watts, D. M., \& Osborne, R. J. (1982). Students' conceptions of ideas in mechanics. Phys. Educ. 17, 62-6.

[8] Halloun, I. A., \&Hestenes, D. (1985). Common sense concepts about motion. American Journal of Physics, 53(11), 1056-1065.

[9] Vygotsky, L. (1986). Thought and Language. Cambridge, MA: The MIT Press.

[10] Beichner, R. J. (1994). Testing student interpretation of kinematics graphs. American Journal of Physics, 62, 750-762.

[11] Besson, U., \&Viennot, L. (2004). Using models at the mesoscopic scale in teaching physics: Two experimental interventions in solid friction and fluid statics. International Journal of Science Education, 26(9), 1083-1110.

[12] Eryilmaz, A. (2002). Effects of conceptual assignments and conceptual change discussions on students' misconceptions and achievement regarding force and motion. Journal of Research in Science Teaching, 39(10), 1001-1015.

[13] McDermott, L. C., \& Shaffer, P. S. (1992). Research as a guide for curriculum development: An example from introductory electricity. Part I: Investigation of student understanding. American Journal of Physics, 60, 994-1013.

[14] Vosniadou, S. (2002). On the nature of naive physics. In M. Limon \& L. Mason (Eds.), Reconsidering conceptual change: Issues in theory and practice (pp. 61-76). Dordrecht, The Netherlands: Kluwer.

[15] Comins, N. F. (1993). Misconceptions about astronomy: Their origins. In Novak, J. D. (Ed.), Proceedings of the 3rd International Seminar on Misconceptions in Science and Mathematics, Cornell University, Cornell.

[16] Diakidoy, I. A., Vosniadou, S., \& Hawks, J. D. (1997). Conceptual change in astronomy: Models of the earth and of the day/night cycle in American-Indian children. European Journal of Psychology of Education, 12(2), 159-184.

[17] Dunlop, J. (2000). How children observe the universe. Publications of the Astronomical Society of Australia, 17(02), 194-206.

[18] Hannust, T., \&Kikas, E. (2007). Children's knowledge of astronomy and its change in the course of learning. Early Childhood Research Quarterly, 22(1), 89-104.

[19] Hannust, T., \&Kikas, E. (2010). Young children's acquisition of knowledge about the earth: A longitudinal study. Journal of Experimental Child Psychology, 107(2), 164-180.

[20] Panagiotaki, G., Nobes, G., \& Potton, A. (2009). Mental 
models and other misconceptions in children's understanding of the earth. Journal of Experimental Child Psychology, 104(1), 52-67.

[21] Barnett, M., \&Morran, J. (2002). Addressing children's alternative frameworks of the Moon's phases and eclipses. International Journal of Science Education, 24(8), 859-879.

[22] Trundle, K. C., Atwood, R. K., Christopher, J. E., \&Sackes, M. (2010). The effect of guided inquiry-based instruction on middle school students' understanding of lunar concepts. Research in Science Education, 40(3), 451-478.

[23] Vosniadou, S., \& Brewer, W. F. (1992). Mental models of the earth: A study of conceptual change in childhood. Cognitive Psychology, 24(4), 535-585.

[24] Park, S. K. (2013). The relationship between students' perception of the scientific models and their alternative conceptions of the lunar phases. Eurasia Journal of Mathematics, Science \& Technology Education, 9(3), 285-299.

[25] Testa, I., Leccia, S., \&Puddu, E. (2014). Astronomy textbook images: do they really help students?. Physics Education, 49(3), 332.

[26] Trumper, R. (2001). A cross-age study of senior high school students' conceptions of basic astronomy concepts. Research in Science \& Technological Education, 19(1), 97-109.

[27] Sadler, P. M. (1992). The initial knowledge state of high school astronomy students. Doctoral dissertation, Harvard University.

[28] Kanli, U. (2014). A Study on Identifying the Misconceptions of Pre-service and In-service Teachers about Basic Astronomy Concepts. Eurasia Journal of Mathematics, Science \& Technology Education, 10(5), 471-479.

[29] OganBekiroglu, F. (2007). Effects of model-based teaching on pre-service physics teachers' conceptions of the moon, moon phases, and other lunar phenomena. International Journal of Science Education, 29(5), 555-593.

[30] Frede, V. (2006). Preservice elementary teacher's conceptions about astronomy. Advances in Space Research, 38(10), $2237-2246$

[31] Trundle, K. C., Atwood, R. K., \& Christopher, J. E. (2006). Preservice elementary teachers' knowledge of observable moon phases and pattern of change in phases. Journal of Science Teacher Education, 17(2), 87-101.

[32] Suzuki, M. (2003). Conversations about the moon with prospective teachers in Japan. Science Education, 87(6), 892-910.

[33] Trumper, R. (2003). The need for change in elementary school teacher training - a cross-college age study of future teachers' conceptions of basic astronomy concepts. Teaching and Teacher Education, 19(3), 309-323.

[34] Trundle, K. C., Atwood, R. K., \& Christopher, J. E. (2002). Preservice elementary teachers' conceptions of moon phases before and after instruction. Journal of Research in Science
Teaching, 39(7), 633-658.

[35] Abell, S., Martini, M., \& George, M. (2001). 'That's what scientists have to do': preservice elementary teachers' conceptions of the nature of science during a moon investigation. International Journal of Science Education, 23(11), 1095-1109.

[36] Trumper, R. (2000). University students' conceptions of basic astronomy concepts. Physics Education, 35(1), 9-15.

[37] Zeilik, M., Schau, C., Mattern, N., Hall, S., Teague, K. W., \&Bisard, W. (1997). Conceptual astronomy: A novel model for teaching postsecondary science courses. American Journal of Physics, 65(10), 987-996.

[38] Brunsell, E., \&Marcks, J. (2004). Identifying a baseline for teachers' astronomy content knowledge. Astronomy Education Review, 3(2), 38-46.

[39] Atwood, R. K., \& Atwood, V. A. (1996). Preservice elementary teachers' conceptions of the causes of seasons. Journal of Research in Science Teaching, 33(5), 553-563.

[40] Bailey, J. M., \& Slater, T. F. (2003). A review of astronomy education research. Astronomy Education Review, 2(2), $20-45$.

[41] Bogdan, R. C., \&Biklen, S. K. (1998). Qualitative research in education. An introduction to theory and methods. Allyn \& Bacon, A Viacom Company, 160 Gould St., Needham Heights, MA.

[42] Lightman, A. P., Miller, J. D., \&Leadbeater, B. J. (1987). Contemporary Cosmological Beliefs, in Misconceptions and Educational Strategies in Science and Mathematics, Vol. III, ed. J. D. Novak, Ithaca, NY: Cornell University Press, 309.

[43] Prather, E. E., Slater, T. F., \&Offerdahl, E. G. (2002). Hints of a fundamental misconception in cosmology. Astronomy Education Review, 1(2), 28-34.

[44] Atwood, R. K., \& Atwood, V. A. (2005). Preservice elementary teachers' conceptions of what causes Night and Day. School Science and Mathematics, 95, 290-294.

[45] Parker, J., \& Heywood, D. (1998). The earth and beyond: developing primary teachers' understanding of basic astronomical events. International Journal of Science Education, 20(5), 503-520.

[46] Vosniadou, S. (1989). Knowledge Acquisition in Observational Astronomy. http://files.eric.ed.gov/fulltext/ED316408.pdf 12.04.2015.

[47] Yair, Y., Schur, Y., \&Mintz, R. (2003). A “Thinking Journey" to the planets using scientific visualization technologies: Implications to astronomy education. Journal of Science Education and Technology, 12(1), 43-49.

[48] Yu, K. C. (2005). Digital full-domes: The future of virtual astronomy education. Planetarian, 34(3), 6-11.

[49] Türk, C., \&Kalkan, H. (2015). The effect of planetariums on teaching specific astronomy concepts. Journal of Science Education and Technology, 24(1), 1-15. 